\title{
Photobiomodulation in Oral Surgery: A Review
}

\author{
Sepanta Hosseinpour, DDS, MPH, PhD Student, ${ }^{1}$ Jan Tunér, DDS, ${ }^{2}$ \\ and Reza Fekrazad, DDS, PhD, FLD, FICD ${ }^{3,4}$
}

\begin{abstract}
Objective: This article presents a review of current data on the applications of photobiomodulation (PBM) in the field of oral and maxillofacial surgery (OMFS), to guide future research.

Background data: Photobiomodulation therapy (PBMT) has been reported to be effective for various postoperative conditions, including pain relief, improvement of mastication, neurosensory recovery, and wound healing. There is a need for identifying the therapeutic irradiation windows for these conditions, based upon the available literature.

Materials and methods: All original articles related to PBM for oral surgery in MEDLINE (NCBI PubMed and PMC), EMBASE, Scopus, Cochrane library, Web of Science, and Google Scholar were reviewed until December 2018.

Results: Forty-six clinical trials were included in this study. These trials were categorized into three different types of PBM applications. After reviewing all these studies, the most effective physical properties for PBM pain reduction after tooth extraction were as follows: wavelength $650-980 \mathrm{~nm}$; power $4-300 \mathrm{~mW}$; and energy density $3-85.7 \mathrm{~J} / \mathrm{cm}^{2}$. PBMT at $660-910 \mathrm{~nm}$ with $4-500 \mathrm{~mW}$ power and $2-480 \mathrm{~J} / \mathrm{cm}^{2}$ energy density was effective for decreasing facial swelling. At the same wavelength and power range with $4-106 \mathrm{~J} / \mathrm{cm}^{2}$ energy density, PBM was effective for alleviating trismus after tooth extraction.

Conclusions: Most papers suggested that PBM seemed to be effective in reducing pain, swelling, and trismus after third molar tooth extraction, neurosensory and nerve recovery after mandibular ramus osteotomy. The heterogeneity of the standardization regarding the parameters of laser calls for caution in interpretation of these results. However, this evidence-based review regarding the best protocols for OMFS applications can be beneficial for both future research and clinical applications.
\end{abstract}

Keywords: low-level laser therapy, photobiomodulation, oral and maxillofacial surgery, oral surgery

\section{Introduction}

A FTER THE ADVENT OF MEDICAL LASERS, numerous applications in many fields of medicine have been reported. Nowadays, low-powered lasers are viewed as an integral part of various therapeutic modalities. ${ }^{1-4}$ Therefore, it becomes pivotal to understand and know the mechanisms and rationale of photobiomodulation (PBM) to apply it more efficiently.

The use of PBM in oral and maxillofacial surgery (OMFS) has seen a substantial increase in various postoperative purposes, including pain relief, improvement of mastication, neurosensory recovery, and wound healing.

Short time modulation of inflammation and acute pain relief with PBM have been demonstrated. ${ }^{5-8}$ PBM causes a biological impact by absorption of its photons by tissues and cellular structures. 9 In addition, expected therapeutic impacts arise from this interaction. For instance, relief of acute pain, acceleration of the healing process, and muscle relaxation are all results from enhanced cellular energy and alterations in cellular membrane permeability. PBM favors

\footnotetext{
${ }^{1}$ School of Dentistry, Oral Health Centre, The University of Queensland, Brisbane, Australia.

${ }^{2}$ Private Practice, Swedish Laser Medical Society (SLMS), Stockholm, Sweden.

${ }^{3}$ Radiation Sciences Research Center, Laser Research Center in Medical Sciences, AJA University of Medical Sciences, Tehran, Iran.

${ }^{4}$ International Network for Photo Medicine and Photo Dynamic Therapy (INPMPDT), Universal Scientific Education and Research Network (USERN), Tehran, Iran.
} 
the hyperpolarized state, directly over primary nerve endings, inhibiting transmission of painful stimuli to the central nervous system. ${ }^{10} \mathrm{PBM}$ also promotes rapid effects in reducing the level of pain and inflammatory mediators such as prostaglandin E2, interleukin 1 (IL1), tumor necrosis factor, and cyclooxygenase 2 (COX-2). ${ }^{11,12}$

A number of studies have demonstrated that PBM has an impact on the management of pain and swelling., 13-18 Ferrante reported that PBM is useful for pain reduction after impacted third molar surgery. ${ }^{19}$ In an animal study, it has been shown that PBM could reduce pain intensity, inflammation, and immunological reactions; while in human studies some factors including the type of disease, surgery, and laserrelated variables influence the outcome of PBM. ${ }^{20}$ A study by Sanz-Moliner et al. $^{21}$ demonstrated that PBM can diminish pain and reduce swelling compared with a control group in patients with severe chronic periodontitis who underwent flap surgery. Several studies have reported an impact of PBM on postoperative complications, pain, neurosensory recovery, and wound healing. Due to the discrepancy between reported investigations, the current systematic review aims to comprehensively review all available documents on the current applications of PBM in the field of OMFS.

\section{Materials and Methods}

\section{Protocol and eligibility criteria}

This review is organized and followed Preferred Reporting Items for Systematic Reviews and Meta-Analyses (PRISMA) guidelines. ${ }^{22}$

Types of studies. All clinical trials, which administrated PBM in oral and maxillofacial field as a therapeutic approach and reported the results of PBM with reasonable account of the used light parameters. In vivo and in vitro studies, systematic and literature reviews, letter to editors, and theses were omitted.

Types of participants. All types of animal models (such as rats and primates) and high-level laser therapy (such as carbon dioxide laser) were excluded and only clinical studies were included.

Types of interventions. Studies investigating PBM in the field of OMFS, including relief of acute/chronic pain, loss of movement, masticatory malfunction, trismus, wound healing, and other therapeutic goals, were included. Studies that did not primarily investigate therapeutic PBM in OMFS or related to the surgical procedures such as incision or removal of tissues were excluded.

Types of outcome measures. These included level of pain in extraction socket or related trigger points, mandibular mobility, patients' anxiety related to pain, neurosensory recovery, and masticatory muscle's tenderness reported by any of the following tests: visual analog scale (VAS), 3dMD face photogrammetric, edema scales, or 2-point discrimination test.

\section{Information sources}

MEDLINE (NCBI PubMed and PMC), EMBASE, Scopus, Cochrane library, Web of Science, and Google Scholar were the information sources. Moreover, a hand search was performed specifically in the following journals; Lasers in Medical Science, Journal of Photochemistry and Photobiology B, Photomedicine and Laser Surgery, Tissue Engineering: Part A, Lasers in Surgery and Medicine, and Journal of Dental Research.

\section{Search strategy}

An electronic search was conducted in PubMed from January 1990 to December 2018, limited to English language publications. Published papers on PBM in oral surgery (pain control, edema, neurosensory recovery, etc.) were found using the following keywords alone or ensemble: ("Laser Therapy"[Mesh] OR "Low-Level light Therapy"'[Mesh] OR "low-intensity laser therapy"[Mesh] OR "Laser Phototherapy"[Mesh] OR "Photobiomodulation Therapy"[Mesh] OR “Low-Level Laser Irradiation”'[Mesh]) AND ("Surgery, Oral"[Mesh] OR "Oral surgical procedures"'[Mesh] OR "osteotomy" [Mesh] OR "tooth extraction").

In addition, manual search of the articles in the selected journals was carried out.

\section{Study selection and data extraction}

Two independent experienced reviewers analyzed all retrieved articles based on their keywords, titles, and abstracts. After initial assessment, included studies were analyzed based on their full text and in the case of disagreement between two reviewers, a third expert person was involved to resolve it by discussing. All steps were performed based on the PRISMA statement.

\section{Data items}

Data were summarized as follows: (1) author and year of publication; (2) laser properties, including laser type, wavelength, power, and energy density; (3) therapeutic purposes; (4) sample size; (5) treatment protocol and location of laser application; (6) method of evaluation; (7) follow-up period; and (8) outcomes of study.

\section{Results}

\section{Study selection}

Fifty articles were retrieved from Medline and 67 articles from other databases, and one study from hand search (Fig. 1PRISMA flow chart). A total of 118 articles were initially screened by two independent reviewers, and 40 studies were excluded due to duplication and unrelated keywords according to our study design. After exclusion of nonrelevant articles, the full texts of 78 studies were evaluated. Within these studies, 32 of them were excluded since they were review studies, case reports, or did not report laser properties. Finally, 46 studies were selected and analyzed in this systematic review. All these studies are summarized in Tables 1-3.

\section{Therapeutic applications of PBM in OMFS; protocols and benefits}

Pain, edema, and trismus

After tooth extraction. Thirty-three clinical trials were included according to the inclusion criteria, investigating the 


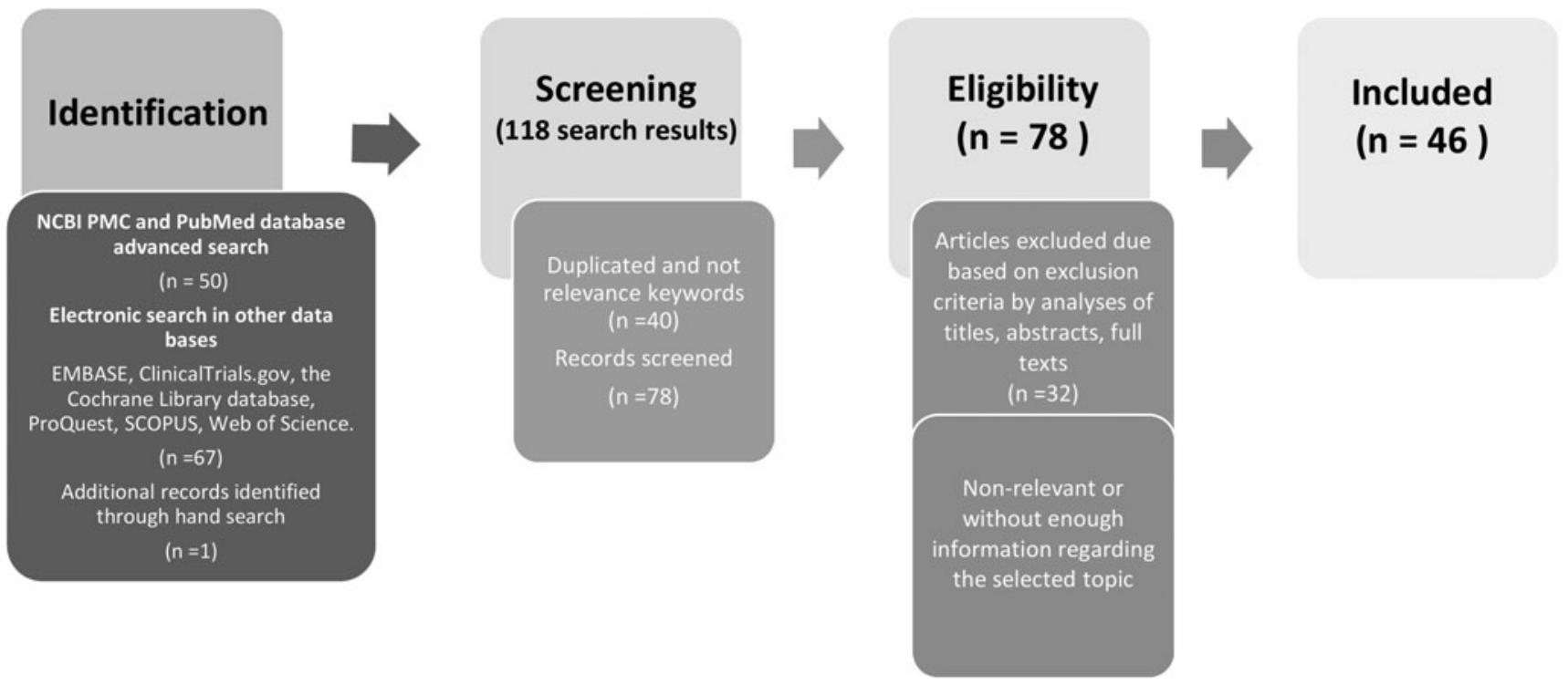

FIG. 1. Study design flow chart based on the Preferred Reporting Items for Systematic Reviews and Meta-Analyses statement.

impact of PBM on pain/swelling/trismus after tooth extraction (Table 1). In all these studies, the third molar was the extracted tooth except in one study conducted on premolar's extraction sockets. ${ }^{23}$ PBM effectively reduced post extraction pain as shown in 16 studies $^{5,6,13,15-19,24-31}$ compared with placebo. In these studies, wavelengths ranged from 650 to $980 \mathrm{~nm}$. In addition, powers were between 4 and $300 \mathrm{~mW}$, and energy densities were between 3 and $85.7 \mathrm{~J} / \mathrm{cm}^{2}$. The outcomes were evaluated by VAS, 3dMD face photogrammetric, maximum mouth opening, and facial distance measuring. PBM was applied both extraorally and/or intraorally. Nonsignificant impact of PBM on pain relief in comparison with placebo was observed in 10 articles. $^{23,32-40}$ Eight of these latter studies applied $\sim 810 \mathrm{~nm}$ diode lasers ${ }^{23,34-40}$ with various powers $(30-500 \mathrm{~mW})$ and energy densities $\left(2-60 \mathrm{~J} / \mathrm{cm}^{2}\right)$.

Facial swelling was assessed in 24 clinical trials. ${ }^{5,13-19,24}$ 26,28-31,33,34,37-43 Among these studies, 10 articles represented significant decrease in facial swelling after PBM application (wavelength: 660-910 nm; power: 4-500 $\mathrm{mW}$; energy density: $2-480 \mathrm{~J} / \mathrm{cm}^{2}$ ) compared with placebo. ${ }^{13-19,31,41-43}$

Twenty studies assessed the impact of PBM on postoperative trismus. ${ }^{5,13,14,16,17,19,24-26,28-31,33,34,37-39,42,43}$ The wavelengths between 660 and $980 \mathrm{~nm}$ with power between 4 and $300 \mathrm{~mW}$ and $4-106 \mathrm{~J} / \mathrm{cm}^{2}$ energy density were reported as significant in reducing postoperative trismus in comparison with placebo. ${ }^{13,14,16,19,31,42,43}$ In general, extraoral irradiation offered better results, especially for edema.

After orthognathic and minor oral surgeries. One clinical trial investigated pain and swelling after orthognathic surgery, ${ }^{44}$ and another one on secondary palatal operation. ${ }^{45}$ One article reported the impact of PBM on mouth opening after orthognathic surgery and surgically assisted rapid maxillary expansion (SARME). ${ }^{46}$ In total, 112 patients participated in these studies. The wavelengths ranged between 660 and $985 \mathrm{~nm}$ with $20-2000 \mathrm{~mW}$ power and $5-100 \mathrm{~J} / \mathrm{cm}^{2}$ energy density. The outcomes were evaluated by distance measurements and VAS. PBM in all studies was significantly effective compared with placebo. In addition, PBM in orthognathic cases was more effective than SARME cases for enhancing maximum mouth opening after 21 days. ${ }^{46}$

Neurosensory recovery. Neurosensory recovery was assessed in nine studies; six studies after mandibular ramus osteotomy, ${ }^{47-52}$ and three of them after various oral surgeries $^{53-55}$ (Table 2). Six studies represented a wide range of effective PBM parameters for nerve recovery after mandibular ramus osteotomy (wavelength: $632-830 \mathrm{~nm}$; power: 20 $100 \mathrm{~mW}$; energy density: $\left.2-32 \mathrm{~J} / \mathrm{cm}^{2}\right) .{ }^{47-52}$ In addition, three other studies showed positive impact of PBM on inferior alveolar nerve (IAN) paresthesia after various oral surgeries such as orthognathic surgery. ${ }^{53-55}$ de Oliveira et al., ${ }^{54}$ in a 3year retrospective study, reported that gallium, aluminum, arsenide (GaAlAs) diode $808 \mathrm{~nm}$ at $100 \mathrm{~mW}$ and $100 \mathrm{~J} / \mathrm{cm}^{2}$ was more effective than placebo in treating IAN paresthesia.

Other applications. In five articles, investigators used PBM after oral surgical procedures ${ }^{23,56-59}$ for applications other than those previously mentioned (Table 3). In three studies, GaAlAs diodes were used, ${ }^{23,56,57}$ in one study a gallium arsenide diode ${ }^{59}$ and in one (60 Monea) a red lightemitting diode (LED) was used. The wavelengths ranged from 620 to $904 \mathrm{~nm}$ with $100-270 \mathrm{~mW}$ power and $46-180 \mathrm{~J} / \mathrm{cm}^{2}$ energy density. In total, 299 patients had participated in these studies. Saliva immunoglobulin A (IgA) and lysosome level, neovascularization, bone and wound healing, and the level of inflammatory and osteogenic markers were analyzed by radial immunodiffusion method, immunohistochemistry, VAS, realtime polymerase chain reaction, and radiographic evaluations. All studies found PBM as an effective treatment modality in comparison with placebo, except in the study of Paschoal and Santos-Pinto. ${ }^{23}$ These authors applied $830 \mathrm{~nm}$ diode laser for wound healing and pain relief after premolar tooth extractions, and indicated nonsignificant impact of PBM after 15 days. 


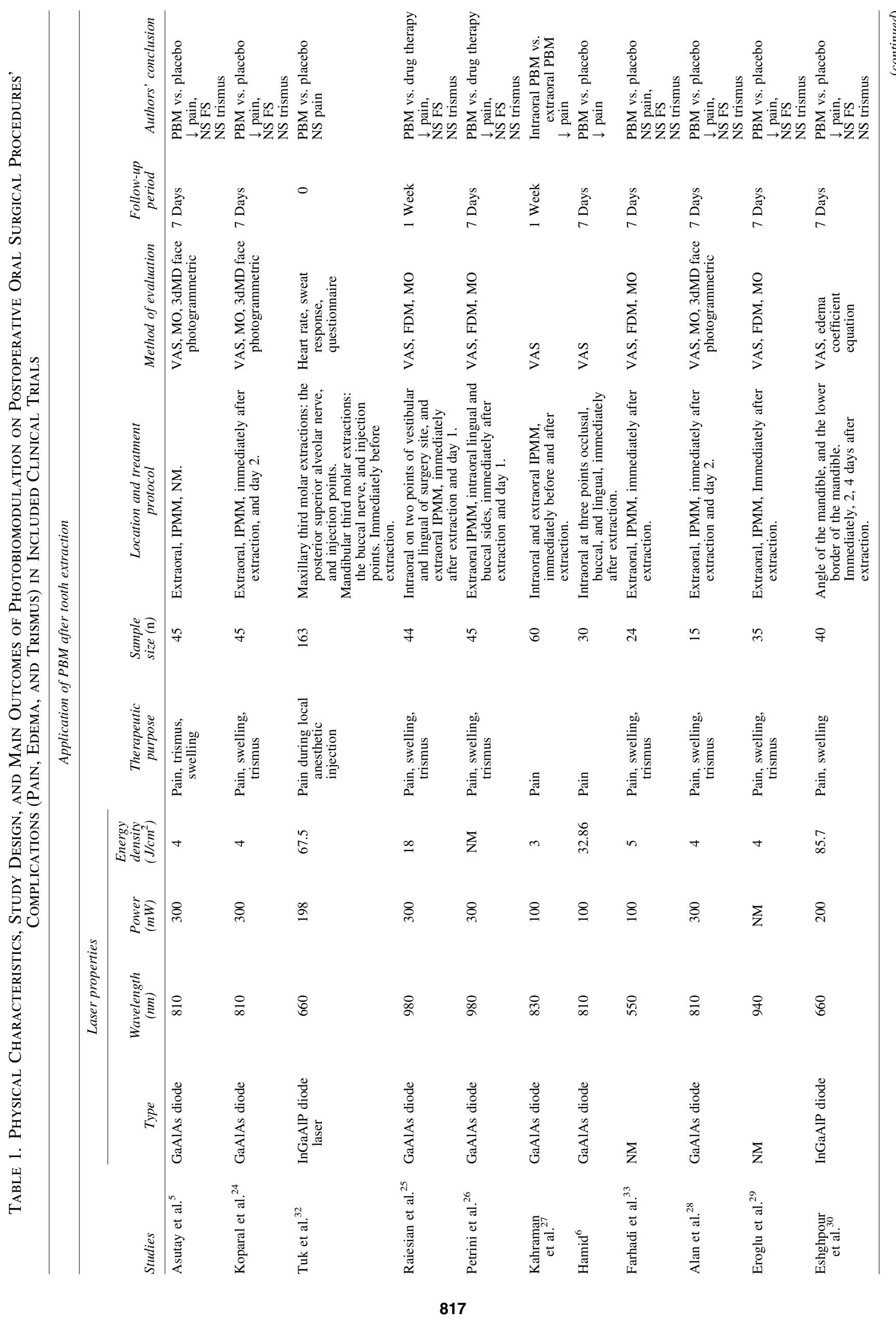




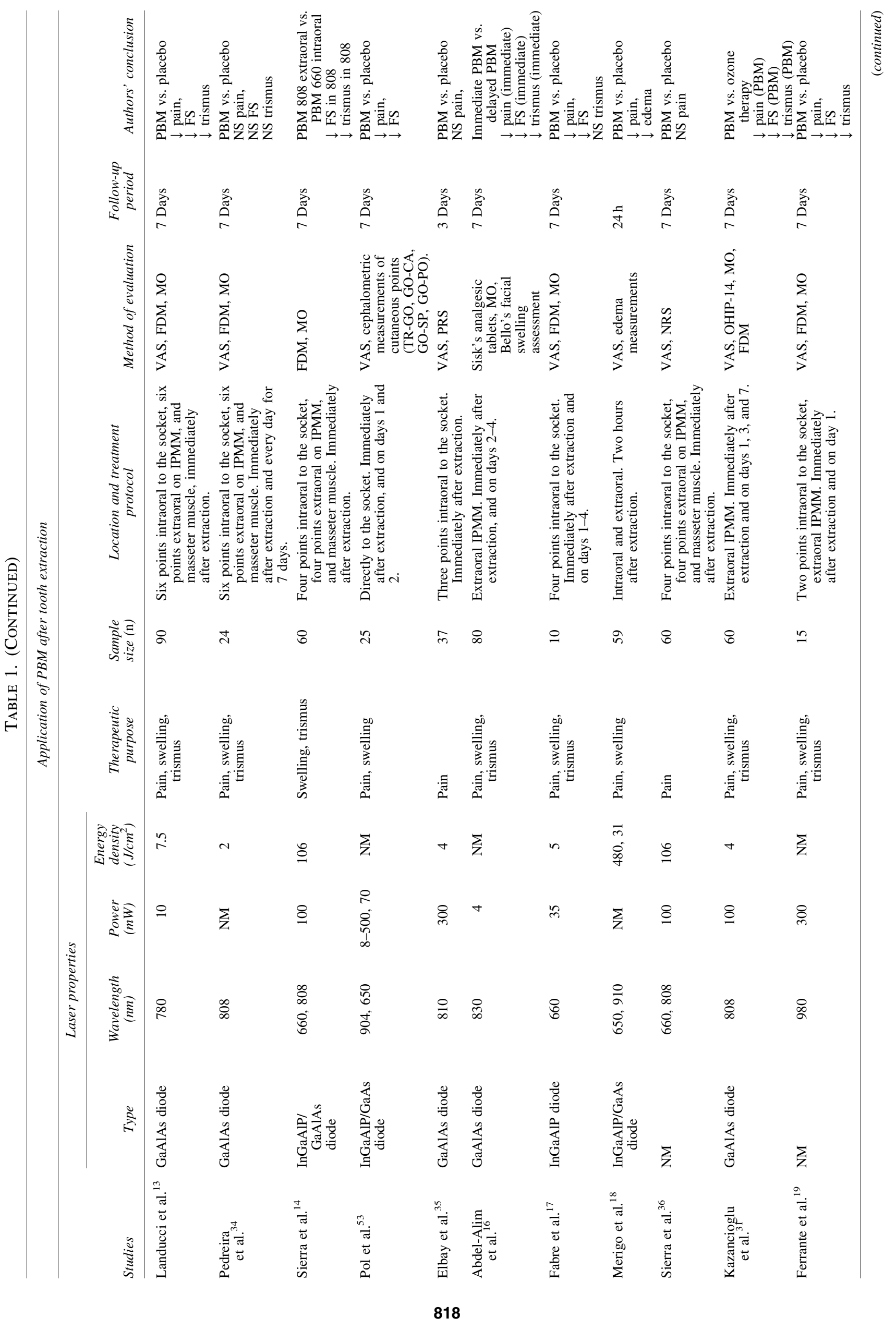




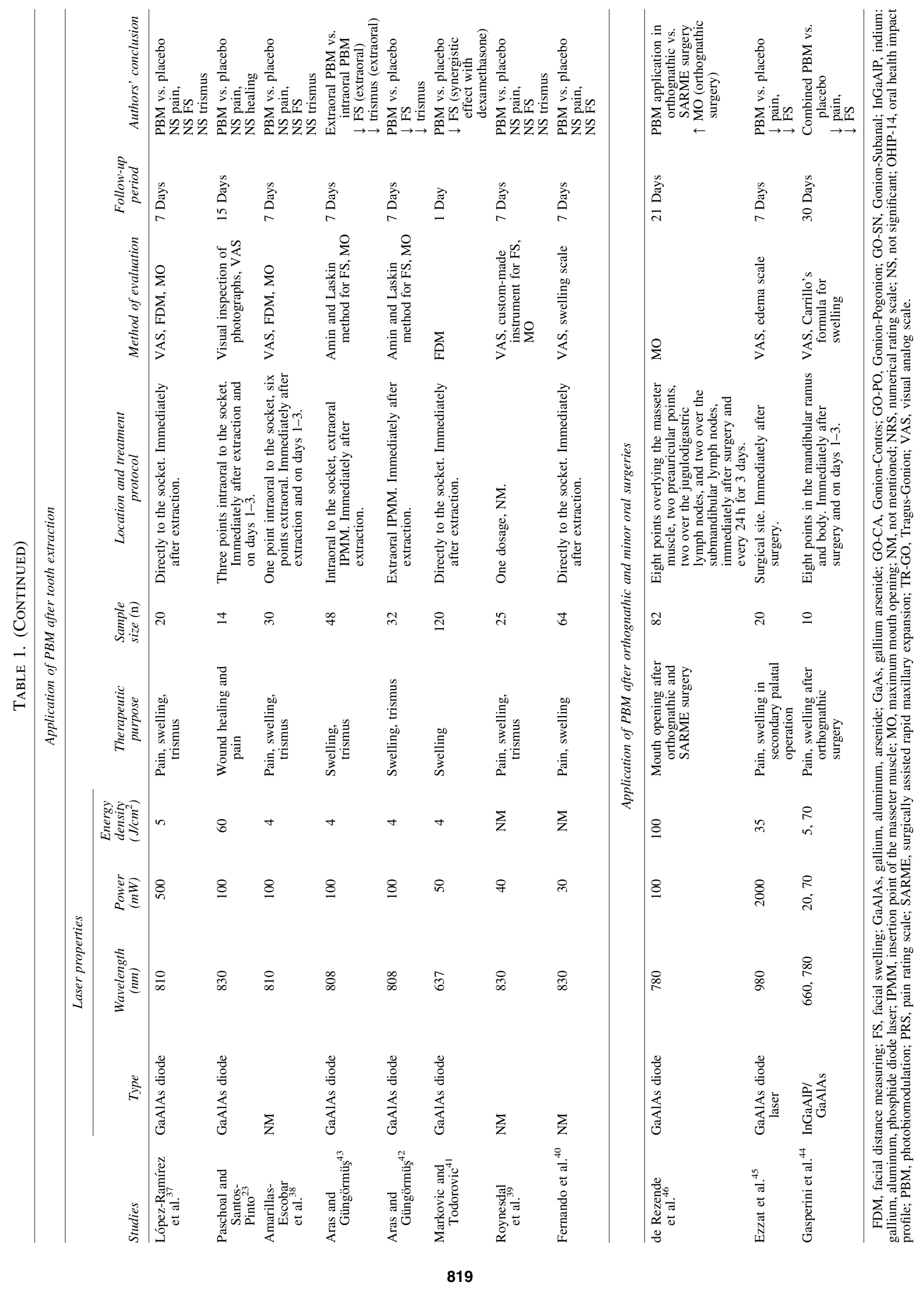




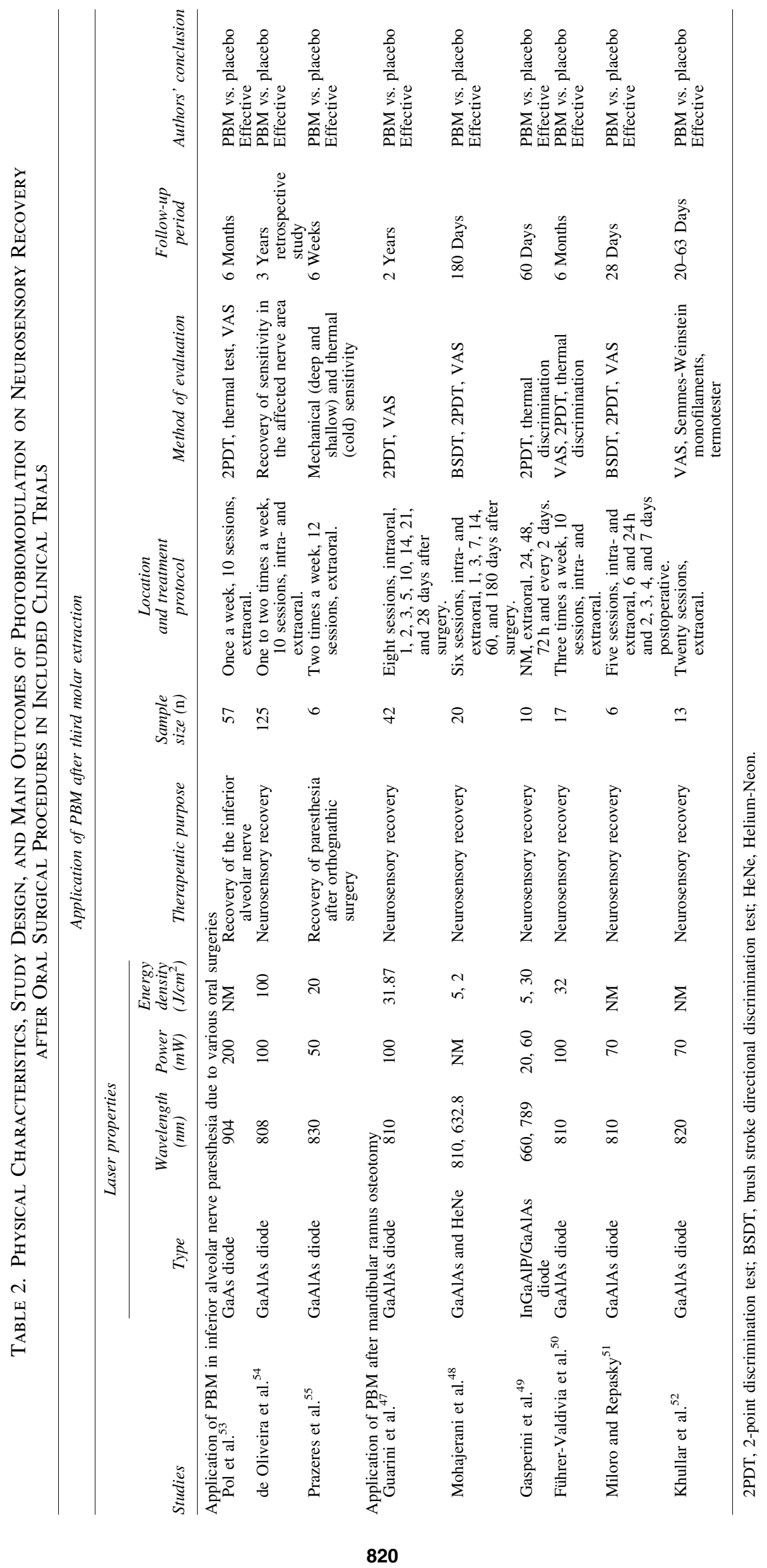




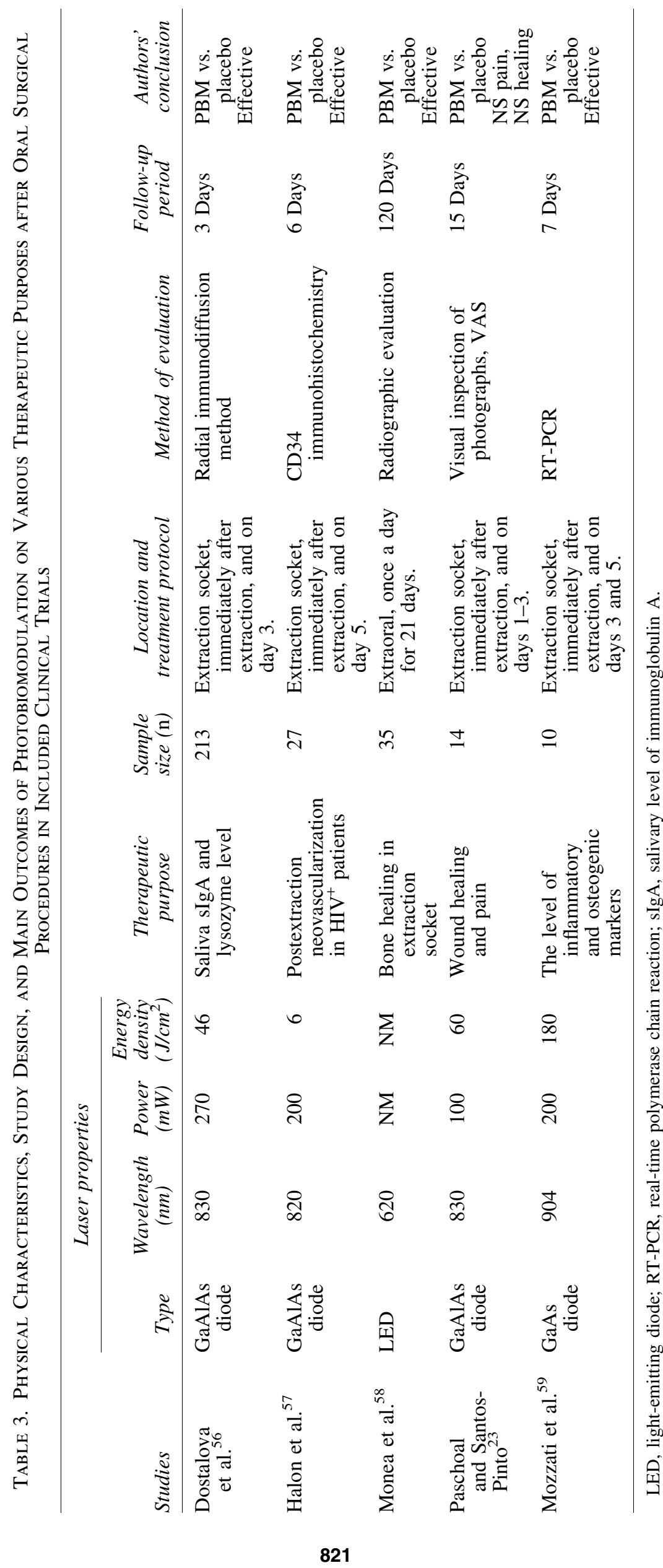




\section{Discussion}

\section{Pain, edema, and trismus}

In this systematic review including 33 studies, PBM was used for the treatment of postoperative major complications such as pain, edema, and trismus in various oral surgeries such as tooth extraction, maxillary expansion, and orthognathic surgeries. The review revealed that most of these studies (18 of 30 articles assessing pain) demonstrated a positive impact of PBM on pain, especially during the first days; whereas some investigations reported nonsignificant results. In addition, it was concluded that PBM seems to be effective in enhancing maximum mouth opening by $4-5 \mathrm{~mm} 7$ days after surgery. However, performing an evidence-based decision based on these studies is difficult due to their study design heterogeneity and contradictory findings. For example, Amarillas-Escobar et al. ${ }^{38}$ reported no significant differences in the level of pain, facial swelling, and trismus between irradiated and placebo groups $\left(810 \mathrm{~nm} ; 100 \mathrm{~mW} ; 4 \mathrm{~J} / \mathrm{cm}^{2}\right)$. On the contrary, in a similar study ( $\left.808 \mathrm{~nm} ; 100 \mathrm{~mW} ; 4 \mathrm{~J} / \mathrm{cm}^{2}\right)$, Kazancioglu et al. ${ }^{31}$ demonstrated a significant reduction in all three variables, not only in comparison with the placebo group but also compared with ozone therapy after 7 days. In addition, Aras and Güngörmüs, in two separate studies in $2010^{43}$ and $2009,{ }^{42}$ observed that PBM $\left(808 \mathrm{~nm} ; 100 \mathrm{~mW} ; 4 \mathrm{~J} / \mathrm{cm}^{2}\right)$ significantly reduced pain and trismus, especially after extraoral applications. In contrast, López-Ramírez et al. ${ }^{37}$ revealed that $810 \mathrm{~nm}$ diode laser with $5 \mathrm{~J} / \mathrm{cm}^{2}$ energy density had no beneficial impact on facial swelling, trismus, and pain.

Farhadi et al. ${ }^{33}$ reported that $550 \mathrm{~nm}$ PBM adjuvant treatment is not clinically helpful for decreasing pain, swelling, and trismus. The authors concluded that administration of analgesics and antibiotics may play the most imperative role and camouflage the impact of PBM in these cases. Further, the low penetration rate of $550 \mathrm{~nm}$ might be considered. In similarity to this study, other investigations reported no evidence of difference between PBM and placebo groups. ${ }^{23,32-40}$ In these negative studies, various medications have been prescribed. For instance, López-Ramírez et al. ${ }^{37}$ recommended $750 \mathrm{mg}$ amoxicillin (every $8 \mathrm{~h}$ for 7 days) and ibuprofen (every $8 \mathrm{~h}$ for 2 days). Moreover, patients in the study by AmarillasEscobar et al. ${ }^{38}$ received amoxicillin $(750 \mathrm{mg})$, acetaminophen $(500 \mathrm{mg}$ ), and ketorolac (30 mg for severe pain).

In contrast to these results, other investigations stated a significant impact. Eshghpour et al. ${ }^{30}$ designed a split-mouth randomized controlled trial, conducted on 40 patients with similar bilateral impacted mandibular third molars. In the lasertreated side, patients received $660 \mathrm{~nm}(200 \mathrm{~mW})$ intraoral and $810 \mathrm{~nm}(200 \mathrm{~mW})$ extraoral irradiation. All patients were advised to receive amoxicillin (500 mg) and ibuprofen $(400 \mathrm{mg})$. Their findings represented significantly lower pain and swelling after 7 days. In addition, all these disagreements observed between various findings in clinical trials could be attributed to the various administrated wavelengths, powers, energy densities, and location of irradiation (intraoral vs. extraoral). Moreover, received medications before or after oral surgical procedures may play a significant role in the outcomes of the trials.

\section{Neurosensory recovery}

Nine clinical trials were included in this section, all of them reporting PBM as an effective therapeutic approach for neurosensory recovery. Some oral and maxillofacial surgical procedures can cause injuries to various nerve tracts, especially the IAN. ${ }^{60-62}$ Bilateral sagittal split osteotomy (BSSO) in mandibular ramus is one of the most critical procedures for IAN injuries. ${ }^{52,63,64}$ Mohajerani et al. ${ }^{48}$ and Guarini et al. ${ }^{47}$ demonstrated that $810 \mathrm{~nm}$ diode laser can effectively enhance neurosensory functions after 6 months and 2 years. Gasperini et al. ${ }^{49}$ revealed the effectiveness of PBM after BSSO, accelerating the recovery period on the irradiated side. This study reports an $86 \%$ improvement in VAS scores and a 96\% improvement in brush stroke at 2 months postoperatively. Moreover, the present systematic review found three articles, ${ }^{53-55}$ which demonstrated the effectiveness of PBM during or shortly after oral and maxillofacial surgical procedure in reducing pain and enhancing neural function in paresthesia. The investigation by Pol et al. ${ }^{53}$ showed that the sensitivity of the lower lip and chin in all patients to the laser-treated side as well as to the placebo side was improved. However, the recovery on the laser-treated side was faster. This suggests an accelerating impact of PBM on the neural healing process. These findings were in agreement with de Oliveira et al. ${ }^{54}$ and Prazeres et al. ${ }^{55}$ Although promising, the actual effect of PBM administration is difficult to determine due to the multifactorial essence of PBM.

\section{Other applications}

This analysis found that the application of PBM was not limited to postoperative pain, edema, and neurosensory injuries. In fact, five clinical studies were included in this systematic review, ${ }^{24,56-59}$ evaluating other potential impacts of PBM after oral and maxillofacial surgeries. Dostalova et al. ${ }^{56}$ observed that PBM application after tooth extraction has an immunological impact. The investigators reported that there is a positive relationship between salivary level of $\operatorname{IgA}$ and lysozyme after $830 \mathrm{~nm}$ laser irradiation performed directly to the extracted tooth socket. $\operatorname{IgA}$ is an antibody that plays an important role in mucosal immunity. In addition, lysozyme is responsible for anti-Gram-positive bacterial resistance. These findings confirmed a positive immunological impact of PBM, which can support the healing process.

In a study by Halon et al., ${ }^{57} 820 \mathrm{~nm}$ PBM application in HIV-positive patients showed significant enhancement in neovascularization. The authors concluded that the positive effect of PBM is not dependent on $\mathrm{CD} 4^{+}$lymphocytes. Monea et al. ${ }^{58}$ also showed that $620 \mathrm{~nm}$ LED extraoral PBM application for 21 days can effectively improve bone healing after 60 days. Bone extraction samples before the placement of implant demonstrated a promotion and maturation of osteoblasts.

Collagen fibers as an important part of bone formation matrix are increased after PBM administration. In agreement with this clinical finding, Posten et al. ${ }^{65}$ demonstrated that PBM can induce proliferation of human gingival fibroblasts and expression of collagen type I gene in vitro.

Several signaling pathways participate in bone formation as a complicated process. ${ }^{66,67} \mathrm{PBM}$ can effectively alter RUNX-2 expression. ${ }^{68-73}$ Moreover, it increases the electrons' availability in the catalytic center of COX. Previous studies measured expression of COX-2 by IHC analy$\operatorname{sis}^{72,74,75}$ and found higher expression of COX-2, especially 
first days after surgery. ${ }^{74,75}$ It has been suggested that expression of COX-2 can be beneficial for bone healing. In early stage of bone formation, $\mathrm{COX}-2$ is associated with the maturation of osteoblasts and modulating differentiation genes. ${ }^{76-78}$ In this regard, Mozzati et al. ${ }^{59}$ investigated PBM impacts on IL-1b, IL-6, IL-10, and COX-2 in a split-mouth designed study on 10 healthy individuals after similar tooth extractions. The investigators demonstrated that $904 \mathrm{~nm}$ diode laser with $200 \mathrm{~mW}$ power and $180.5 \mathrm{~J} / \mathrm{cm}^{2}$ energy density can significantly impede the expression of inflammatory markers.

\section{Consensus conclusions and future direction}

In the included studies, the physical properties of the most effective PBM parameters for pain reduction after tooth extraction were as follows: wavelength, $650-980 \mathrm{~nm}$; power, 4-300 $\mathrm{mW}$; and energy density, 3-85.7 J/ $/ \mathrm{cm}^{2}$. PBM application at $660-910 \mathrm{~nm}$ with $4-500 \mathrm{~mW}$ power and $2-480 \mathrm{~J} / \mathrm{cm}^{2}$ energy density was effective for decreasing facial swelling; and at the same wavelength and power range with $4-106 \mathrm{~J} / \mathrm{cm}^{2}$ energy density it was effective for alleviating trismus after tooth extraction. We identified several wavelengths $\sim 800 \mathrm{~nm}, \pm 30 \mathrm{~nm}$. It is unclear if these are physically verified by the investigators, or due to diode quality variations. Nor have we been able to verify a biological difference of a specific wavelength in this narrow spectrum. In addition, PBM has been applied successfully for nerve recovery after mandibular ramus osteotomy (wavelength: 632-830 nm; power: $20-100 \mathrm{~mW}$; energy density: $2-32 \mathrm{~J} / \mathrm{cm}^{2}$ ). The use of PBM can prove to be an effective tool in the management of a wide variety of conditions with greater efficiency than is currently possible. The great variation in light parameters seen in positive as well as negative studies urges future researchers to look for the optimal application when it comes to parameters such as dose, energy, time of illumination, and number of sessions. Due to the heterogeneity of the studies and parameters, we were not able to perform a quantitative analysis of the data.

\section{Author Disclosure Statement}

No competing financial interests exist.

\section{Funding Information}

There was no funding provided for this article.

\section{References}

1. Madhumathi D, Kumar M. Low-level laser therapy in oral and maxillofacial surgery-A review. Drug Invention Today 2018;10:685-691.

2. Xu G-Z, Jia J, Jin L, Li J-H, Wang Z-Y, Cao D-Y. Lowlevel laser therapy for temporomandibular disorders: a systematic review with meta-analysis. Pain Res Manag 2018;2018:4230583.

3. Moskvin VS, Apolikhin IO. Effectiveness of low level laser therapy for treating male infertility. Biomedicine 2018;8:e108.

4. Zokaee H, Zahmati AHA, Mojrian N, Boostani A, Vaghari M. Efficacy of low-level laser therapy on orofacial pain: a literature review. Adv Hum Biol 2018;8:70.

5. Asutay F, Ozcan-Kucuk A, Alan H, Koparal M. Threedimensional evaluation of the effect of low-level laser therapy on facial swelling after lower third molar surgery: a randomized, placebo controlled study. Nigerian J Clin Pract 2018;21:1107-1113.

6. Hamid MA. Low-level laser therapy on postoperative pain after mandibular third molar surgery. Ann Maxillofac Surg 2017;7:207-216.

7. Dawdy J, Halladay J, Carrasco-Labra A, Araya I, Yanine $\mathrm{N}$, Brignardello-Petersen R. Efficacy of adjuvant laser therapy in reducing postsurgical complications after the removal of impacted mandibular third molars: a systematic review update and meta-analysis. J Amer Dent Ass 2017; 148:887.e884-902.e884.

8. Balevi B. Efficacy of adjuvant laser therapy in reducing postsurgical complications after the removal of impacted mandibular third molars: a systematic review update and meta-analysis. J Evid Based Dent Pract 2018;18:162-164.

9. Farivar S, Malekshahabi T, Shiari R. Biological effects of low level laser therapy. J Lasers Med Sci 2014;5:58-62.

10. Carroll JD, Milward MR, Cooper PR, Hadis M, Palin WM. Developments in low level light therapy (LLLT) for dentistry. Dent Mater 2014;30:465-475.

11. Bjordal JM, Johnson MI, Iversen V, Aimbire F, LopesMartins RAB. Low-level laser therapy in acute pain: a systematic review of possible mechanisms of action and clinical effects in randomized placebo-controlled trials. Photomed Laser Surg 2006;24:158-168.

12. Hosseinpour S, Fekrazad R, Arany PR, Ye Q. Molecular impacts of photobiomodulation on bone regeneration: a systematic review. Prog Biophys Mol Biol 2019; Apr 17. [Epub ahead of print]; DOI:10.1016/j.pbiomolbio.2019.04.005.

13. Landucci A, Wosny A, Uetanabaro L, Moro A, Araujo M. Efficacy of a single dose of low-level laser therapy in reducing pain, swelling, and trismus following third molar extraction surgery. Int J Oral Maxillofac Surg 2016;45:392-398.

14. Sierra SO, Deana AM, Bussadori SK, et al. Choosing between intraoral or extraoral, red or infrared laser irradiation after impacted third molar extraction. Lasers Surg Med 2016;48:511-518.

15. Pol R, Ruggiero T, Gallesio G, et al. Efficacy of antiinflammatory and analgesic of superpulsed low level laser therapy after impacted mandibular third molars extractions. J Craniofac Surg 2016;27:685-690.

16. Abdel-Alim HM, Abdel-Dayem H, Mustafa ZA, Bayoumi A, Jan A, Jadu F. A comparative study of the effectiveness of immediate versus delayed photobiomodulation therapy in reducing the severity of postoperative inflammatory complications. Photomed Laser Surg 2015;33:447-451.

17. Fabre HS, Navarro RL, Oltramari-Navarro PV, et al. Antiinflammatory and analgesic effects of low-level laser therapy on the postoperative healing process. J Phys Ther Sci 2015;27:1645-1648.

18. Merigo E, Vescovi P, Margalit M, et al. Efficacy of LLLT in swelling and pain control after the extraction of lower impacted third molars. Laser Ther 2015;24:39-46.

19. Ferrante M, Petrini M, Trentini P, Perfetti G, Spoto G. Effect of low-level laser therapy after extraction of impacted lower third molars. Lasers Med Sci 2013;28:845849.

20. Fekrazad R, Chiniforush N, Bouraima SA, et al. Low level laser therapy in management of complications after intra oral surgeries. J Lasers Med Sci 2012;3:135.

21. Sanz-Moliner JD, Nart J, Cohen RE, Ciancio SG. The effect of an 810-nm diode laser on postoperative pain and tissue response after modified Widman flap surgery: a pilot study in humans. J Periodont 2013;84:152-158. 
22. Moher D, Shamseer L, Clarke M, et al. Preferred Reporting Items for Systematic Review and Meta-Analysis protocols (PRISMA-P) 2015 statement. Syst Rev 2015;4:1.

23. Paschoal MAB, Santos-Pinto L. Therapeutic effects of lowlevel laser therapy after premolar extraction in adolescents: a randomized double-blind clinical trial. Photomed Laser Surg 2012;30:559-564.

24. Koparal M, Ozcan Kucuk A, Alan H, Asutay F, Avci M. Effects of low-level laser therapy following surgical extraction of the lower third molar with objective measurement of swelling using a three-dimensional system. Exp Ther Med 2018;15:3820-3826.

25. Raiesian S, Khani M, Khiabani K, Hemmati E, Pouretezad M. Assessment of low-level laser therapy effects after extraction of impacted lower third molar surgery. J Laser Med Sci 2017;8:42-45.

26. Petrini M, Ferrante M, Trentini P, Perfetti G, Spoto G. Effect of pre-operatory low-level laser therapy on pain, swelling, and trismus associated with third-molar surgery. Med Oral Patol Oral Cir Bucal 2017;22:e467-e472.

27. Kahraman SA, Cetiner S, Strauss RA. The effects of transcutaneous and intraoral low-level laser therapy after extraction of lower third molars: a randomized single blind, placebo controlled dual-center study. Photomed Laser Surg 2017;35:401-407.

28. Alan H, Yolcu Ü, Koparal M, Özgür C, Öztürk SA, Malkoç $\mathrm{S}$. Evaluation of the effects of the low-level laser therapy on swelling, pain, and trismus after removal of impacted lower third molar. Head Face Med 2016;12:25.

29. Eroglu CN, Keskin Tunc S. Effectiveness of single session of low-level laser therapy with a $940 \mathrm{~nm}$ wavelength diode laser on pain, swelling, and trismus after impacted third molar surgery. Photomed Laser Surg 2016;34:406-410.

30. Eshghpour M, Ahrari F, Takallu M. Is low-level laser therapy effective in the management of pain and swelling after mandibular third molar surgery? J Oral Maxillofac Surg 2016;74:1321-1322.

31. Kazancioglu HO, Ezirganli S, Demirtas N. Comparison of the influence of ozone and laser therapies on pain, swelling, and trismus following impacted third-molar surgery. Lasers Med Sci 2014;29:1313-1319.

32. Tuk JGC, van Wijk AJ, Mertens IC, Keles Z, Lindeboom JAH, Milstein DMJ. Analgesic effects of preinjection lowlevel laser/light therapy (LLLT) before third molar surgery: a double-blind randomized controlled trial. Oral Surg Oral Med Oral Pathol Oral Radiol 2017;124:240-247.

33. Farhadi F, Eslami H, Majidi A, et al. Evaluation of adjunctive effect of low-level laser Therapy on pain, swelling and trismus after surgical removal of impacted lower third molar: a double blind randomized clinical trial. Laser Ther 2017;26:181-187.

34. Pedreira AA, Wanderley F, Sa M, et al. Thermographic and clinical evaluation of 808-nm laser photobiomodulation effects after third molar extraction. Minerva Stomatol 2016; 65:213-222.

35. Elbay ÜŞ, Tak Ö, Elbay M, Uğurluel C, Kaya C. Efficacy of low-level laser therapy in the management of postoperative pain in children after primary teeth extraction: a randomized clinical trial. Photomed Laser Surg 2016;34: 171-177.

36. Sierra SO, Deana AM, Bussadori SK, et al. Effect of lowintensity laser treatment on pain after extraction of impacted mandibular third molars: a randomised, controlled, clinical trial. Br J Oral Maxillofac Surg 2015;53:9961000 .

37. López-Ramírez M, Vílchez-Pérez MÁ, Gargallo-Albiol J, Arnabat-Domínguez J, Gay-Escoda C. Efficacy of low-level laser therapy in the management of pain, facial swelling, and postoperative trismus after a lower third molar extraction. A preliminary study. Lasers Med Sci 2012;27:559566.

38. Amarillas-Escobar ED, Toranzo-Fernández JM, MartínezRider R, et al. Use of therapeutic laser after surgical removal of impacted lower third molars. J Oral Maxillofac Surg 2010;68:319-324.

39. Roynesdal A, Björnland T, Barkvoll P, Haanaes H. The effect of soft-laser application on postoperative pain and swelling: a double-blind, crossover study. Int J Oral Maxillofac Surg 1993;22:242-245.

40. Fernando S, Hill C, Walker R. A randomised double blind comparative study of low level laser therapy following surgical extraction of lower third molar teeth. Br J Oral Maxillofac Surg 1993;31:170-172.

41. Markovic A, Todorovic L. Effectiveness of dexamethasone and low-power laser in minimizing oedema after third molar surgery: a clinical trial. Int J Oral Maxillofac Surg 2007;36:226-229.

42. Aras $M H$, Güngörmüş $M$. The effect of low-level laser therapy on trismus and facial swelling following surgical extraction of a lower third molar. Photomed Laser Surg 2009;27:21-24.

43. Aras MH, Güngörmüş M. Placebo-controlled randomized clinical trial of the effect two different low-level laser therapies (LLLT) - intraoral and extraoral—on trismus and facial swelling following surgical extraction of the lower third molar. Lasers Med Sci 2010;25:641-645.

44. Gasperini G, de Siqueira IR, Costa LR. Does low-level laser therapy decrease swelling and pain resulting from orthognathic surgery? Int J Oral Maxillofac Surg 2014;43: 868-873.

45. Ezzat AE, EL-Shenawy HM, El-Begermy MM, Eid MI, Akel MM, Abbas AY. The effectiveness of low-level laser on postoperative pain and edema in secondary palatal operation. Int J Pediatr Otorhinolaryngol 2016;89:183-186.

46. de Rezende RA, Silva DN, Frigo L. Effect of GaAlAs lowlevel laser therapy on mouth opening after orthognathic surgery. Lasers Med Sci 2018;33:1271-1277.

47. Guarini D, Gracia B, Ramirez-Lobos V, Noguera-Pantoja A, Sole-Ventura P. Laser biophotomodulation in patients with neurosensory disturbance of the inferior alveolar nerve after sagittal split ramus osteotomy: a 2-year follow-up study. Photomed Laser Surg 2018;36:3-9.

48. Mohajerani SH, Tabeie F, Bemanali M, Tabrizi R. Effect of low-level laser and light-emitting diode on inferior alveolar nerve recovery after sagittal split osteotomy of the mandible: a randomized clinical trial study. J Craniofac Surg 2017;28:e408-e411.

49. Gasperini G, de Siqueira ICR, Costa LR. Lower-level laser therapy improves neurosensory disorders resulting from bilateral mandibular sagittal split osteotomy: a randomized crossover clinical trial. J Cranio-Maxill Surg 2014;42: e130-e133.

50. Führer-Valdivia A, Noguera-Pantoja A, Ramírez-Lobos V, Solé-Ventura P. Low-level laser effect in patients with neurosensory impairment of mandibular nerve after sagittal split ramus osteotomy. Randomized clinical trial, 
controlled by placebo. Med Oral Patol Oral Cir Bucal 2014;19:e327-e334.

51. Miloro M, Repasky M. Low-level laser effect on neurosensory recovery after sagittal ramus osteotomy. Oral Surg Oral Med Oral Pathol Oral Radiol Endod 2000;89:12-18.

52. Khullar SM, Emami B, Westermark A, Haanes HR. Effect of low-level laser treatment on neurosensory deficits subsequent to sagittal split ramus osteotomy. Oral Surg Oral Med Oral Pathol Oral Radiol Endod 1996;82:132-138.

53. Pol R, Gallesio G, Riso M, et al. Effects of superpulsed, low-level laser therapy on neurosensory recovery of the inferior alveolar nerve. J Craniofac Surg 2016;27:12151219.

54. de Oliveira RF, da Silva AC, Simoes A, Youssef MN, de Freitas PM. Laser therapy in the treatment of paresthesia: a retrospective study of 125 clinical cases. Photomed Laser Surg 2015;33:415-423.

55. Prazeres LDKT, Muniz YVS, Barros KMA, de Martinez Gerbi MEM, Laureano Filho JR. Effect of infrared laser in the prevention and treatment of paresthesia in orthognathic surgery. J Craniofac Surg 2013;24:708-711.

56. Dostalova T, Kroulikova V, Podzimek S, Jelinková H. Low-level laser therapy after wisdom teeth surgery: evaluation of immunologic markers (secretory immunoglobulin A and lysozyme levels) and thermographic examination: placebo controlled study. Photomed Laser Surg 2017;35: 616-621.

57. Halon A, Donizy P, Dziegala M, Dobrakowski R, Simon K. Tissue laser biostimulation promotes post-extraction neoangiogenesis in HIV-infected patients. Lasers Med Sci 2015;30:701-706.

58. Monea A, Beresescu G, Tibor M, Popsor S, Antonescu DM. Bone healing after low-level laser application in extraction sockets grafted with allograft material and covered with a resorbable collagen dressing: a pilot histological evaluation. BMC Oral Health 2015; 15:134.

59. Mozzati M, Martinasso G, Cocero N, et al. Influence of superpulsed laser therapy on healing processes following tooth extraction. Photomed Laser Surg 2011;29:565-571.

60. Bhat P, Cariappa K. Inferior alveolar nerve deficits and recovery following surgical removal of impacted mandibular third molars. J Maxillofac Oral Surg 2012;11:304-308.

61. Nguyen E, Grubor D, Chandu A. Risk factors for permanent injury of inferior alveolar and lingual nerves during third molar surgery. J Maxillofac Oral Surg 2014;72:23942401.

62. Gülicher D, Gerlach K. Sensory impairment of the lingual and inferior alveolar nerves following removal of impacted mandibular third molars. Int J Oral Maxillofac Surg 2001; 30:306-312.

63. Bagheri SC, Meyer RA, Khan HA, Wallace J, Steed MB. Microsurgical repair of the peripheral trigeminal nerve after mandibular sagittal split ramus osteotomy. J Oral Maxillofac Surg 2010;68:2770-2782.

64. Bagheri SC. Microsurgical repair of the peripheral trigeminal nerve after mandibular sagittal split ramus osteotomy. J Oral Maxillofac Surg 2008;66:34.

65. Posten W, Wrone DA, Dover JS, Arndt KA, Silapunt S, Alam M. Low-level laser therapy for wound healing: mechanism and efficacy. Dermatol Surg 2005;31:334-340.

66. Hoffmann A, Gross G. BMP signaling pathways in cartilage and bone formation. Crit Rev Eukar Gene 2001;11: 23-45.
67. Yang J, Andre P, Ye L, Yang Y-Z. The Hedgehog signaling pathway in bone formation. Int J Oral Sci 2015;7:73-79.

68. Wang Y, Huang Y-Y, Wang Y, Lyu P, Hamblin MR. Photobiomodulation (blue and green light) encourages osteoblastic-differentiation of human adipose-derived stem cells: role of intracellular calcium and light-gated ion channels. Sci Rep 2016;6:33719.

69. Tim CR, Bossini PS, Kido HW, et al. Effects of low-level laser therapy on the expression of osteogenic genes during the initial stages of bone healing in rats: a microarray analysis. Lasers Med Sci 2015;30:2325-2333.

70. Magri AMP, Fernandes KR, Assis L, et al. Photobiomodulation and bone healing in diabetic rats: evaluation of bone response using a tibial defect experimental model. Lasers Med Sci 2015;30:1949-1957.

71. Park JB, Ahn S-J, Kang Y-G, Kim E-C, Heo JS, Kang KL. Effects of increased low-level diode laser irradiation time on extraction socket healing in rats. Lasers Med Sci 2015; 30:719-726.

72. Tim CR, Pinto KNZ, Rossi BRO, et al. Low-level laser therapy enhances the expression of osteogenic factors during bone repair in rats. Lasers Med Sci 2014;29:147156.

73. Patrocínio-Silva TL, de Souza AMF, Goulart RL, et al. The effects of low-level laser irradiation on bone tissue in diabetic rats. Lasers Med Sci 2014;29:1357-1364.

74. Matsumoto MA, Ferino RV, Monteleone GF, Ribeiro DA. Low-level laser therapy modulates cyclo-oxygenase-2 expression during bone repair in rats. Lasers Med Sci 2009; 24:195-201.

75. Tim CR, Bossini PS, Kido HW, et al. Effects of low level laser therapy on inflammatory and angiogenic gene expression during the process of bone healing: a microarray analysis. J Photochem Photobiol B Biol 2016;154:8-15.

76. Sato Y, Arai N, Negishi A, Ohya K. Expression of cyclooxygenase genes and involvement of endogenous prostaglandin during osteogenesis in the rat tibial bone marrow cavity. J Med Dent Sci 1997;44:81-92.

77. Forwood M. Inducible cyclo-oxygenase (COX-2) mediates the induction of bone formation by mechanical loading in vivo. J Bone Miner Res 1996;11:1688-1693.

78. Zhang X, Schwarz EM, Young DA, Puzas JE, Rosier RN, O'Keefe RJ. Cyclooxygenase-2 regulates mesenchymal cell differentiation into the osteoblast lineage and is critically involved in bone repair. J Clin Invest 2002;109:14051415.

Address correspondence to:

Reza Fekrazad, DDS, PhD, FLD, FICD

Radiation Sciences Research Center

Lasers Research Center in Medical Sciences AJA University of Medical Sciences Flat No. 12, Mooj Building

First Behestan, Pasdaran Street Tehran 1946883893

Iran

E-mail: rezafekrazad@gmail.com

Received: June 12, 2019. Accepted after revision: July 27, 2019. Published online: November 21, 2019. 